\title{
Influence of iron deficiency on thyroidal hormone production in piglets before weaning
}

\author{
Zdeněk Fajt ${ }^{1}$, Tomáš Baňoch ${ }^{2}$, Jan Vašek ${ }^{1}$, Jonáš Vaňhara ${ }^{1}$, Jana Blahová ${ }^{2}$, \\ Zdenka Kazatelová ${ }^{,}$, Emma Fiorino $^{3}$, Martin Svoboda ${ }^{1}$
}

\begin{abstract}
${ }^{1}$ University of Veterinary and Pharmaceutical Sciences Brno, Faculty of Veterinary Medicine, Ruminant and Swine Clinic, ${ }^{2}$ Faculty of Veterinary Hygiene and Ecology, Department of Veterinary Public Health and Animal Welfare, Brno, Czech Republic

${ }^{3}$ University of Messina, Department of Biological and Environmental Sciences, Italy
\end{abstract}

Received October 29, 2015

Accepted December 8, 2015

\begin{abstract}
The aim of this study was to evaluate the influence of iron deficiency on the thyroidal function and hormone $\mathrm{T}_{3}$ and $\mathrm{T}_{4}$ concentration in piglets before weaning. We used 40 Landrace $\times$ Czech Large White piglets before weaning in this trial. They were divided into two groups. The control group was supplemented with iron after birth, the experimental group was without iron supplementation after birth. Iron, $\mathrm{T}_{3}$ and $\mathrm{T}_{4}$ and haematology indicators were observed. Piglets in the experimental group developed serious anaemia. The iron serum concentration in the experimental group was significantly lower than in the control group. Significant difference in $\mathrm{T}_{3}$ and $\mathrm{T}_{4}$ hormone concentration was found between the experimental and the control group. At the age of 17 and 25 days we found the negative effect of iron deficiency on the thyroid hormone production.
\end{abstract}

Haematology, anaemia, supplementation, $T_{3}, T_{4}$

Iron deficiency represents a serious problem in an intensive pig production. Piglets are born physiologically with a limited storage of iron $(50 \mathrm{mg}$ ) (Zimmermann 1995). From the milk or colostrum the piglet can receive only $1 \mathrm{mg}$ of iron $(\mathrm{Fe})$ per day (Kleinbeck and McGlone 1999). However, the daily requirement is $7-10 \mathrm{mg}$ (Venn et al. 1947). Therefore, additional iron supplementation is necessary.

The most common method of iron supplementation is i.m. (intramuscular) injection of iron dextran or other forms of iron. A total dose of $200 \mathrm{mg}$ is usually recommended (Radostits et al. 1994). Without any preventive iron administration anaemia develops in piglets within 10-14 days after birth (Zimmermann 1995). This is characterized as microcytic hypochromic anaemia (Radostits et al. 1994). Besides direct effects of iron deficiency on red blood cell indices, this condition influences also other physiological functions. Iron-deficient piglets have an impaired resistance to infectious and parasitic diseases (Dubansky et al. 1997). Suppression of humoral and cell mediated immunity was demonstrated in several studies (De Wayne et al. 1977; Egeli et al. 1998). Iron-deficient piglets also show considerably lower growth rates than supplemented piglets (Radostits et al. 1994). The mechanism of growth retardation is not completely understood. For instance the function of cytochromic enzymes, especially peroxidase and catalases is dependent on the amount of iron in cells (Bünger et al. 1988).

Other factors to be considered are thyroid hormones. They can influence the metabolic rate and heat loss to environment (Brigham and Beard 1995). The negative effect of iron deficiency on the thyroid function has been demonstrated in several studies. To our knowledge there are no literature data so far regarding this matter in pigs. Therefore, the

Address for correspondence:

MVDr. Zdeněk Fajt, Ph.D.

Ruminant and Swine Clinic

Faculty of Veterinary Medicine

University of Veterinary and Pharmaceutical Sciences Brno

Palackého tř. 1946/1, 61242 Brno, Czech Republic

http://actavet.vfu.cz/ 
aim of the trial was to evaluate the influence of iron deficiency on thyroid hormones in suckling piglets under specific conditions of a farrowing unit.

\section{Materials and Methods}

\section{Experimental design}

A total of 40 piglets of Landrace $\times$ Czech Large White breed before weaning were used in the study. The study was approved by the Ethics Committee of the University of Veterinary and Pharmaceutical Sciences Brno. The piglets were weaned at the age of 28 days. They were kept in the standard conditions of farrowing units. They were kept in the same pens with sows during the trial. Four different litters from four sows were used. They were fed with a standard "KPK diet" (with iron concentration of $160 \mathrm{mg} / \mathrm{kg}$ of feed) 14 days before parturition until weaning. The piglets were fed with a standard feed mixture "Weaning pellets Zn gr" (with iron concentration of $101 \mathrm{mg} / \mathrm{kg}$ of feed) and "Starter gr" (with iron concentration of $101 \mathrm{mg}$ / $\mathrm{kg}$ of feed). We used the principle of divided litters. We chose 4 (5) female piglets and 5 (6) male piglets from each sow and divided them into 2 groups ( 11 male and 9 female of each). All piglets were marked with a plastic ear tag. The piglets were weighed before each sampling. We used standard certificated and serviced laboratory scale to determine the weight of piglets. All animals used in this trial were kept in these groups until weaning. Group E was the experimental group with no iron supplementation after birth. Group $\mathrm{C}$ was the control group with iron supplementation after birth. This control group (C) was given a single i.m. injection of iron in form of the gleptoferronum complex ( $1 \mathrm{ml}$ of Gleptosil inj. $100 \mathrm{ml}$ (CEVA ANIMAL HEALTH Slovakia, s.r.o.), in concentration $200 \mathrm{mg} / \mathrm{ml}$ of preparation) at the age of 3 days. The experimental group (E) was given a single i.m. injection of iron in form of the gleptoferronum complex ( $1 \mathrm{ml}$ of Gleptosil inj. $100 \mathrm{ml}$ (CEVA ANIMAL HEALTH Slovakia, s.r.o.), in concentration $200 \mathrm{mg} / \mathrm{ml}$ of preparation) at the age of 17 days.

\section{Sampling}

Blood samples were taken at days 3,10,17, 26 of age of piglets. Blood was taken from vena cava cranialis (altogether, 80 samples from each group). After sampling, part of the blood sample was coagulated in special sterile tubes with serum accelerators for serum analysis. Concentrations of the thyroid hormones triiodthyronine $\left(\mathrm{T}_{3}\right)$ and tetraiodthyronine $\left(\mathrm{T}_{4}\right)$, and iron were determined. The rest of the blood samples was left in sterile tubes with EDTA for haematology indicators such as red blood cell count (RBC), haemoglobin concentration (HGB), microhaematocrit (PCV), mean corpuscular volume (MCV), mean corpuscular haemoglobin $(\mathrm{MCH})$, and mean corpuscular haemoglobin concentration (MCHC).

$\mathrm{T}_{3}$ and $\mathrm{T}_{4}$ analysis

Before analysis, samples of blood serum were thawed in a refrigerator $\left(2-8^{\circ} \mathrm{C}\right)$. Immulite - Immunoassay Analyzer, (DPC Cirrus Inc., Los Angeles, USA) was used for determination of $\mathrm{T}_{3}$ and $\mathrm{T}_{4}$ in serum. Probe Wash module, Siemens and Probe Cleaning KIT, (Siemens, USA) were used as flush solutions. Competitive enzymatic method was used for the final detection of $\mathrm{T}_{3}$ and $\mathrm{T}_{4}$ concentrations in the sample.

\section{Iron analysis}

The Solaar (Thermo Electron Corporation, England) machine was used for determination of iron in serum. The method of atomic absorption spectrometry was used.

Haematology indicators analysis

Mindway, BC - 2800 Vet. machine was used for analysis of haematology indicators in EDTA blood samples. Dia Rinse D, Medesa, Dia Lyse Diff D-CF, Medesa, Dia EZ Cleanser D, Medesa, Probe Cleanser, Medesa (Czech Republic) were used as flush solutions. The method of colorimetry for detection of $\mathrm{Hb}$ was used. The method of impedance was used for other variables.

\section{Statistical analysis}

Statistical assessment was carried out using Unistat 5.6 for Excel software (Czech Republic). Data were tested for normality (Shapiro-Wilk test). Data did not satisfy normal distribution, therefore, non-parametric MannWhitney $\mathrm{U}$ test was applied to test the differences in measured indices between control and experimental group. Significance was accepted at $P<0.05$. All data are reported as means \pm standard error of the mean.

\section{Results}

\section{$\mathrm{T}_{3}$ and $\mathrm{T}_{4}$ serum concentration}

On day 3 of age of piglets there was no difference between the experimental (Group E) and the control group (Group C). The values were within the physiological range. On the $10^{\text {th }}$ day of age of piglets, a significant difference was found between Group E and Group 
$\mathrm{C}$ in $\mathrm{T}_{3}$ hormone values. The $\mathrm{T}_{3}$ values were within the physiological range in Group E. In $\mathrm{T}_{4}$ hormone values, highly significant difference was found. On day 17 of age of piglets a significant difference was found between Group E and Group $\mathrm{C}$ in $\mathrm{T}_{3}$ hormone values. No differences were found in $\mathrm{T}_{4}$ concentrations. Values in both groups were within the physiological range. On the $26^{t^{4}}$ day of age of piglets a significant difference between Group $\mathrm{E}$ and Group $\mathrm{C}$ was found in $\mathrm{T}_{3}$ and $\mathrm{T}_{4}$ hormone concentrations (Figs 1 and 2).

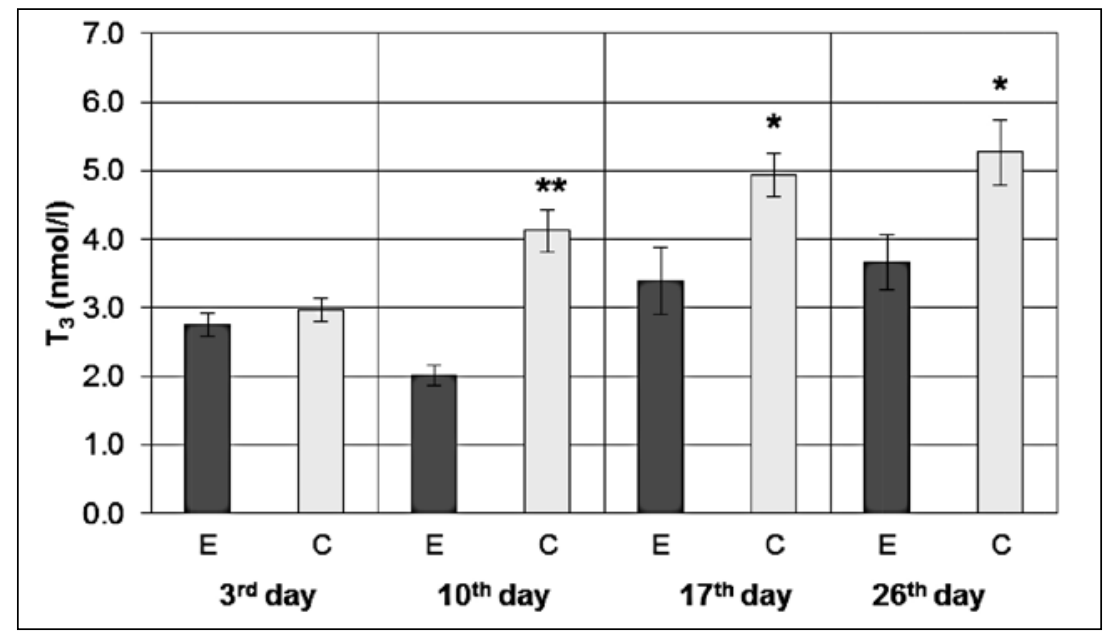

Fig. $1 \mathrm{~T}_{3}$ serum concentration and its difference between experimental (E) and control group (C)

Data are expressed as means \pm standard error of the mean. $\mathrm{E}$ - experimental group; $\mathrm{C}$ - control group; * $P<0.05 ; * * P<0.01$

$\mathrm{T}_{3}=$ triiodthyronin

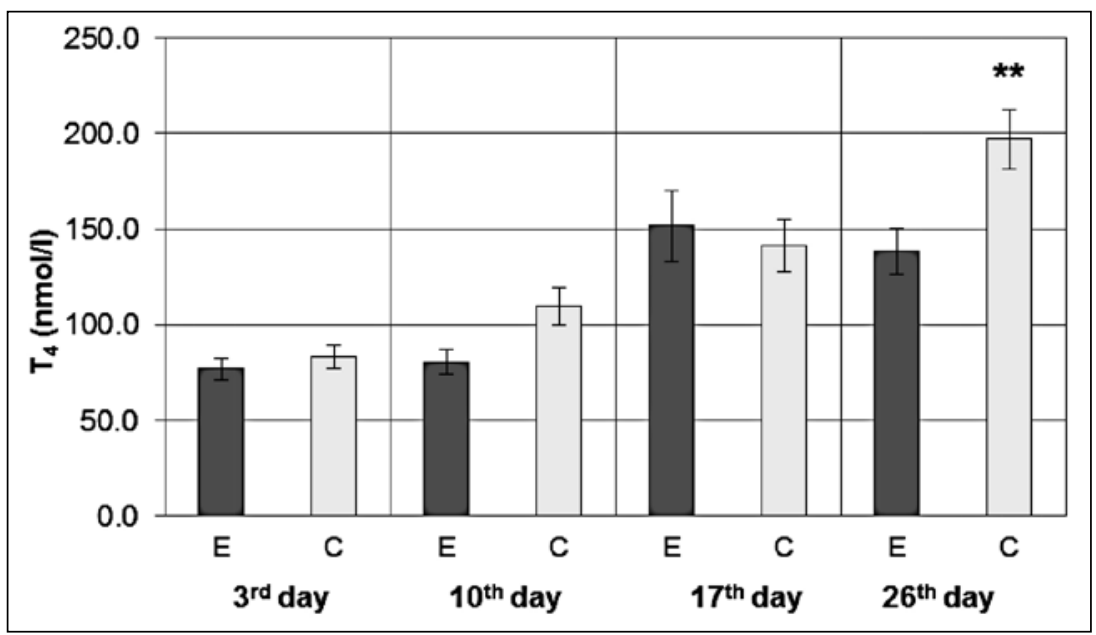

Fig 2. $\mathrm{T}_{4}$ serum concentration and its difference between the experimental $(\mathrm{E})$ and the control group $(\mathrm{C})$

Data are expressed as means \pm standard error of the mean. $\mathrm{E}$ - experimental group; $\mathrm{C}$ - control group;

* $P<0.05$; ** $P<0.01$

$\mathrm{T}_{4}=$ tetraiodthyronin 


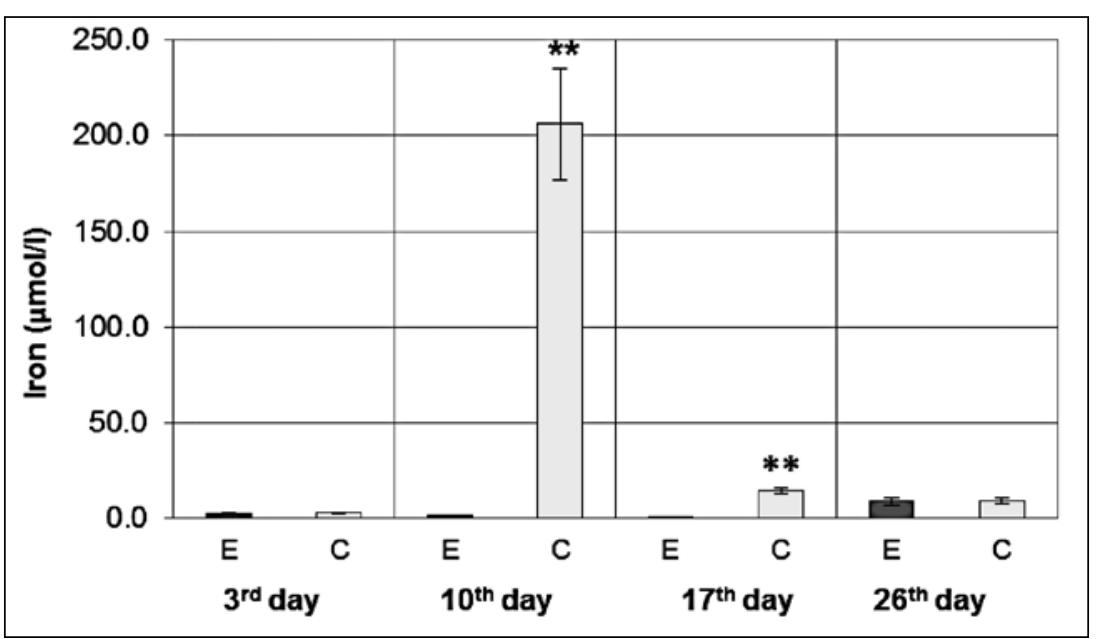

Fig. 3 Iron serum concentration and its difference between the experimental (E) and the control group (C)

Data are expressed as means \pm standard error of the mean. $\mathrm{E}-$ experimental group; $\mathrm{C}-$ control group; $* P<0.05$; $* * P<0.01$

\section{Iron serum concentration}

On the $3^{\text {rd }}$ day of age of piglets there were no differences between the experimental and the control group. Both groups were within the physiological range. On day 10 of age of piglets the iron serum concentrations in the experimental group (Group E) were significantly lower than in the control group (Group C). On the $17^{\text {th }}$ day of age of piglets the iron serum concentrations in Group E were significantly lower than in Group C. On the $26^{\text {th }}$ day of age of piglets there were no differences between Group E and Group C (Fig. 3).

Table 1. Haematology indicators and differences between the experimental (E) and control group (C).

\begin{tabular}{cccccccc}
\hline Day of age & Group & RBC $\left(10^{12} \cdot \mathrm{l}^{-1}\right)$ & $\mathrm{HB}\left(\mathrm{g}^{\cdot-1}\right)$ & $\mathrm{PCV}(\%)$ & $\mathrm{MCV}(\mathrm{f} \cdot \mathrm{l})$ & $\mathrm{MCH}(\mathrm{p} \cdot \mathrm{g})$ & $\mathrm{MCHC}\left(\mathrm{g} \cdot \mathrm{l}^{-1}\right)$ \\
\hline 3 & $\mathrm{E}$ & $4.04 \pm 0.18$ & $70.84 \pm 2.68$ & $20.52 \pm 0.92$ & $51.08 \pm 1.14$ & $17.65 \pm 0.36$ & $347.95 \pm 5.68$ \\
& $\mathrm{C}$ & $3.91 \pm 0.15$ & $67.55 \pm 2.48$ & $19.77 \pm 0.80$ & $50.73 \pm 0.80$ & $17.30 \pm 0.24$ & $342.70 \pm 3.67$ \\
10 & $\mathrm{E}$ & $2.67 \pm 0.17$ & $43.17 \pm 1.92$ & $11.61 \pm 0.65$ & $44.34 \pm 1.11$ & $16.61 \pm 0.56$ & $375.89 \pm 6.40$ \\
& $\mathrm{C}$ & $3.87 \pm 0.16^{* *}$ & $80.78 \pm 3.20^{* *}$ & $24.51 \pm 0.99^{* *}$ & $63.72 \pm 1.14^{* *}$ & $20.91 \pm 0.39^{* *}$ & $329.39 \pm 2.51^{* *}$ \\
17 & $\mathrm{E}$ & $1.86 \pm 0.14$ & $30.82 \pm 1.46$ & $7.86 \pm 0.47$ & $43.18 \pm 0.80$ & $17.10 \pm 0.65$ & $398.12 \pm 11.26$ \\
& $\mathrm{C}$ & $5.01 \pm 0.11^{* *}$ & $97.00 \pm 1.40^{* *}$ & $29.35 \pm 0.45^{* *}$ & $58.88 \pm 0.78^{* *}$ & $19.39 \pm 0.26^{* *}$ & $330.11 \pm 1.04^{* *}$ \\
26 & E & $4.06 \pm 0.23$ & $56.19 \pm 2.38$ & $17.67 \pm 0.84$ & $44.43 \pm 1.53$ & $14.19 \pm 0.56$ & $320.81 \pm 5.53$ \\
& $\mathrm{C}$ & $5.24 \pm 0.11^{* *}$ & $91.56 \pm 1.75^{* *}$ & $27.67 \pm 0.46^{* *}$ & $53.16 \pm 1.01^{* *}$ & $17.51 \pm 0.34^{* *}$ & $330.33 \pm 1.52^{* *}$ \\
\hline
\end{tabular}

Data are expressed as means \pm standard error of the mean. $* * P<0.01$

RBC (red blood cells), HGB (haemoglobin concentration), PCV (microhaematocrit), MCV (mean corpuscular volume), $\mathrm{MCH}$ (mean corpuscular haemoglobin), MCHC (mean corpuscular haemoglobin concentration).

\section{Haematology indicators}

On the $3^{\text {rd }}$ day of age of piglets there was no difference between the experimental (Group E) and the control group (Group C). The values were not within the physiological range. 
On the $10^{\text {th }}$ day of age of piglets, a significant difference between Group E and Group C was found in all haematology indicators. However, in both groups the values were still within the physiological range. On the $17^{\text {th }}$ day of age of piglets a significant difference between Group E and Group C in was found. The control group was within the physiological range. On the $26^{\text {th }}$ day of age of piglets a significant difference between Group E and Group C was found again. The experimental group was still within the physiological range.

The differences in haematology indicators

Table 2. Differences in piglet weight between the experimental (E) and control group (C).

\begin{tabular}{ccl}
\hline Day of age & Group & Weight $(\mathrm{kg})$ \\
\hline 3 & $\mathrm{E}$ & $2.21 \pm 0.09$ \\
& $\mathrm{C}$ & $1.80 \pm 0.07$ \\
10 & $\mathrm{E}$ & $3.00 \pm 0.08^{* *}$ \\
& $\mathrm{C}$ & $3.44 \pm 0.07$ \\
17 & $\mathrm{E}$ & $4.37 \pm 0.09^{* *}$ \\
& $\mathrm{C}$ & $4.73 \pm 0.07$ \\
26 & $\mathrm{E}$ & $6.20 \pm 0.16$ \\
& $\mathrm{C}$ & $6.43 \pm 0.14$ \\
\hline
\end{tabular}

Data are expressed as means \pm standard error of the mean. ** $P<0.01$ between Group E and C are described in Table 1.

\section{Weight of piglets}

On the $3^{\text {rd }}$ day of age of piglets there was no difference between the experimental (Group E) and the control group (Group C). On the $10^{\text {th }}$ day of age of piglets a significant difference between Group $\mathrm{E}$ and Group $\mathrm{C}$ was found in the daily gain; being lower in Group E. On the $17^{\text {th }}$ day of age of piglets a significant difference between Group E and Group $\mathrm{C}$ was found in the daily gain; being lower in Group E. On the $26^{\text {th }}$ day of age of piglets no significant difference was found between Group E and Group C. The different weights in both groups are described in Table 2 .

\section{Discussion}

The effect of iron deficiency on serum concentration of thyroid hormones was evaluated in studies conducted on rats and human patients. It has been found that this deficiency lowers serum thyroid hormone concentrations and impairs peripheral conversion of $\mathrm{T}_{4}$ to $\mathrm{T}_{3}$ (Beard et al. 1989). The result is decreased utilization of thyroid hormones in tissues. The mechanism for these effects is unclear. One possible explanation is altered hypothalamic pituitary thyroid control in iron deficient rats (Beard et al. 1989). The lower peripheral formation of $\mathrm{T}_{3}$ can be related to decreased deiodinase activities caused by iron deficiency. For instance, Beard et al. (1989) demonstrated lower hepatic deiodinase activities in iron deficient rat.

The intensity of thyroid hormones deficiency caused by insufficient iron supply can differ among individuals. It can be influenced by the degree of anaemia, environmental temperature and metabolic rate of the studied organism (Beard et al. 1990).

In this respect, suckling piglets can be considered as a unique subject of study. Piglets that are not supplemented with iron can develop a serious form of anaemia. Suckling piglets have high growth intensity; they double their weight from 1.5 to $3 \mathrm{~kg}$ during the first week (Jain 1986). They normally reach four to five times their birth weight at the end of 3 weeks of age (Radostis et al. 1994). We found lower weight gains in piglets without iron supplementation.

The haemoglobin concentration of $90 \mathrm{~g} \cdot 1^{-1}$ is considered by most authors as the limit, i.e. the point when anaemia starts to manifest by clinical symptoms and begins to exert a detrimental effect on weight (Furugouri 1975). Reference values of 22-36 $\mathrm{mmol} \cdot \mathrm{l}^{-1}$ were given by Steinhardt et al. (1982) for plasma iron concentrations.

It is evident from the results of our study that the piglets in the experimental group developed serious anaemia. The values were found to be below physiological levels starting from the age of two weeks. After treatment with iron of the gleptoferronum complex on day 17 there was significant improvement of red blood cell indictors and iron concentration in blood plasma. As expected, iron deficiency had a detrimental effect on the growth rate of experimental piglets. 
The iron deficiency anaemia had a negative effect on thyroid hormone concentrations under the conditions of our study. The $\mathrm{T}_{3}$ concentrations in the experimental group were found to be lower than the control starting from day 7 of age and remained so till the end of the trial. The $\mathrm{T}_{4}$ concentrations were comparable between experimental and control group during the first three weeks.

Lower values of $\mathrm{T}_{4}$ were detected on day 25 after birth in the experimental group. This indicates that iron deficiency anaemia affected more seriously $T_{3}$ than $T_{4}$ concentrations. The possible explanation is that the impaired peripheral formation of $\mathrm{T}_{3}$ due to decreased deiodinase activities caused by iron deficiency played a more important role than altered hypothalamic pituitary thyroid control.

\section{Acknowledgements}

This research was supported by the Internal Grant Agency 71/2014/FVL, University of Veterinary and Pharmaceutical Sciences Brno, Czech Republic.

\section{References}

Beard JL, Borel MJ, Derr J 1990: Impaired thermoregulation and thyroid function in iron-deficiency anemia. Am J Clin Nut 52: 813-819

Beard J, Tobin B, Green W 1989: Evidence for thyroid hormone deficiency in iron-deficient anemic rats. J Nut 119: $772-778$

Brigham DE, Beard JL 1995: Effect of thyroid hormone replacement in iron-deficient rats. Am J Phys 269: $1140-1147$

Bünger B, Bünger U, Lemke E 1988: Verhaltensbiologische Vitalitätseinschätzung von Ferkeln mit hoch-und mittelgradiger konnataler Eisenmangelanämie. Mh Vet Med 43: 583-587

De Wayne A, Boyd B, Hal H 1977: A new prophylactic approach to reduction of piglet mortality. Med Vet Pract 58: $509-515$

Dubansky V, Zizlavsky M, Drabek J 1997: Myeloperoxidase deficiency in piglets caused by insufficient iron supplementation (In Czech) Veterinářství 47: 205-209

Egeli AK, Framstad T, Morberg H 1998: Clinical biochemistry, hematology and body weight in piglets. Act Vet Scan 39: 381-393

Jain NC 1986: Shalm's Veterinary Haematology (4 ${ }^{\text {th }}$ edn), Lea and Febiger, Philadelphia, pp 240-255

Furugouri K 1975: Characteristic aspects of iron metabolism in piglets. Jap Agr Res 9: 171

Kleinbeck S, McGlone J 1999: Intensive indoor versus outdoor production systems: Genotype and supplemental iron effects on blood hemoglobin and selected immune measures in young pigs. J Anim Sci 77: 2384-2390

Radostits OM, Blood DC, Gay CC 1994: Iron deficiency. In Radostits OM et al.: Veterinary Medicine. Bailliere Tindall, London, pp 1398-1401

Steinhardt M, Bünger U, Furcht G, Shoenfelder E 1982: Beziehungen zwischen Blutbildung und Eisenstoffwechsel beim Ferkel. Arch Exp Vet Med 36: 729-737

Venn JAJ, McCance RA, Widdowson EM 1947: Iron metabolism in piglet anemia. J Comp Pat 57: 314-325

Zimmermann W 1995: Auswirkungen diverser Anämieprohylaxeformen auf die Blutparameter der Saugferkel. Dtsch Tierärztl Wschr 102: 32-38 